\title{
Salivary Biomarkers for Alzheimer's Disease and Related Disorders
}

\author{
Nicholas J. Ashton · Mark Ide · Henrik Zetterberg · Kaj Blennow
}

Received: July 16, 2019 /

(C) The Author(s) 2019

\section{ABSTRACT}

The search for accessible and cost-effective biomarkers to complement current cerebrospinal fluid (CSF) and imaging biomarkers in the accurate detection of Alzheimer disease (AD) and other common neurodegenerative disorders remains a challenging task. The advances in ultra-sensitive detection methods

Enhanced digital features To view enhanced digital features for this article go to https://doi.org/10.6084/ m9.figshare.9792335.

N. J. Ashton $(\varangle) \cdot$ H. Zetterberg $\cdot$ K. Blennow Department of Psychiatry and Neurochemistry, Institute of Neuroscience \& Physiology, The Sahlgrenska Academy at the University of Gothenburg, Mölndal, Sweden

e-mail: nicholas.ashton@gu.se

\section{N. J. Ashton}

Wallenberg Centre for Molecular and Translational Medicine, University of Gothenburg, Gothenburg, Sweden

\section{N. J. Ashton}

King's College London, Institute of Psychiatry, Psychology and Neuroscience, Maurice Wohl Institute Clinical Neuroscience Institute, London, UK

\section{N. J. Ashton}

NIHR Biomedical Research Centre for Mental Health and Biomedical Research Unit for Dementia at South London and Maudsley NHS Foundation, London, UK has highlighted blood biomarkers (e.g. amyloid$\beta$ and neurofilament light) as a valuable and realistic tool in a diagnostic or screening process. Saliva, however, is also a rich source of potential biomarkers for disease detection and offers several practical advantages over biofluids that are currently examined for neurodegenerative disorders. However, while this may be true for the general population, challenges in collecting saliva from an elderly population should be seriously considered. In this review, we begin by discussing how saliva is produced and how age-related conditions can modify saliva production and composition. We then focus on the

\section{Ide}

Periodontology, Centre for Host Microbiome Interactions, Faculty of Dental, Oral and Craniofacial Sciences, King's College London, London, UK

M. Ide

Mucosal and Salivary Biology, Centre for Host Microbiome Interactions, Faculty of Dental, Oral and Craniofacial Sciences, King's College London, London, UK

H. Zetterberg · K. Blennow

Clinical Neurochemistry Laboratory, Sahlgrenska University Hospital, Mölndal, Sweden

\section{H. Zetterberg}

Department of Neurodegenerative Disease, UCL Institute of Neurology, Queen Square, London, UK

\section{H. Zetterberg}

UK Dementia Research Institute at UCL, London, UK 
data available which support the concept of salivary amyloid- $\beta$, tau species and novel biomarkers in detecting AD and alpha-synuclein ( $\alpha$-syn) in Parkinson's disease (PD).

Keywords: Alzheimer's disease; Amyloid- $\beta$; Biomarkers; Parkinson's disease; Saliva; Tau

\section{Key Summary Points}

Peripheral biomarkers for Alzheimer's disease and related disorders have taken centre stage with ultra-sensitive assays developed for amyloid- $\beta$, tau species and neurofilament light.

Saliva is an alternative peripheral source for accessible and non-invasive disease biomarkers.

Total tau, phosphorylated tau, amyloid- $\beta$ and alpha-synuclein proteins are all detectable in saliva and preliminary investigations have shown potential diagnostic utility. Novel candidates (e.g. lactoferrin) could be used for early disease detection.

Standardisation of saliva collection and storage methods are greatly needed to advance this field further.

\section{INTRODUCTION}

The diagnosis of probable Alzheimer's disease (AD) and other common neurodegenerative disorders remains primarily reliant on a clinical assessment outside the specialist clinic. However, an AD diagnosis can now be supported by positron emission tomography (PET) and cerebrospinal fluid (CSF) biomarkers that detect the hallmark-underlying pathologies of amyloid- $\beta$ (A $\beta$ ) [1] and tau [2]. One of the many challenges that the dementia community face is the detection of the pre-symptomatic phase of the $\mathrm{AD}$ using non-invasive, widely accessible and disease relevant biomarkers. In recent times, blood biomarkers have taken

centre stage, with measurements of $\mathrm{A} \beta$ species [3-6], the axonal injury marker neurofilament light $(\mathrm{NfL})[7,8]$ and phosphorylated tau on threonine 181 (P-tau181) [9] showing much promise. There are now international efforts underway to progress these biomarkers to be applicable for clinical use [10]. Without question, a blood biomarker is far more attainable for population screening than PET or CSF; however, it still faces certain logistical limitations. Saliva has been proposed as a potential easily collectable source of biomarkers for the diagnosis and risk assessment for a range of pathological conditions occurring not only in the mouth but also systemically [11]. Disorders that have been targeted include periodontal and oral mucosal diseases, oral, pancreatic, lung and breast cancer, together with diabetes and hepatitis C infection [12]. The major salivary glands secrete saliva in response to cholinergic innervation from cranial nerves VII and IX, which are monitored by the autonomic nervous system (ANS) [13]. This relation to the nervous system suggests that these gland secretions may represent various physiologies of the nervous system. Indeed, central nervous system (CNS) proteins are secreted into the saliva in an age-dependent manner $[14,15]$. Furthermore, via passive diffusion, active transport or microfiltration proteins can pass from the blood into the saliva $[13,16]$. For these reasons, saliva may contain novel biomarkers for CNS injury or be an alternative and more accessible source in sampling AD-related biomarkers that are currently being eagerly pursued in blood. In this review, we summarise the current evidence for salivary biomarkers in detecting $\mathrm{AD}$ and related disorders, while considering important factors related to saliva production, composition and collection in older adults. This article is based on previously conducted studies and does not contain any studies with human participants or animals performed by any of the authors.

\section{PRODUCTION OF SALIVA AND IMPACTS OF AGING, LOCAL AND SYSTEMIC PATHOLOGY}

Saliva collection generally represents a pooled sample of the products from three pairs of major salivary glands (submandibular, sublingual and 
parotid), supplemented by numerous minor salivary glands. In addition, this material includes microorganisms, their by-products, host cells from epithelial surfaces, and other components released from the gingival crevices around teeth (gingival crevicular fluid). Therefore, it is important to understand the processes of production and regulation of saliva, and how this may differ in populations, especially older adults, since any variations may impact on the relative validity of proposed biomarkers.

Saliva production varies between different glands, not only in production volume but also in composition [17]. The exocrine glands contain secreting epithelial cells located in structures called acini as the terminal element of the ductal tree within the gland. Acinar cells will produce either dilute saliva with low levels of mucins or mucin-rich secretion. Whilst the parotid glands largely contain non-mucinous acinar cells, submandibular glands are mixed, whereas the sublingual glands and the minor glands located throughout the mouth are largely mucin forming. The ducts and acini are surrounded by myoepithelial cells, a rich blood supply and dense innervation by parasympathetic and sympathetic nerves. Consequently, the steady unstimulated saliva flow occurring throughout the day is made up primarily of glands producing mucinous saliva; $68 \%$ from submandibular and sublingual, and around 4\% from numerous minor glands. However, when salivary output is stimulated (e.g. during mastication via mucosal and periodontal mechanoreceptors, activated taste bud receptors, smells or thermal changes [18-21]), the percentage contribution from parotid saliva rises from around $1 / 4$ to over $1 / 2$ [22] even though other glands also increase their production. Autonomic innervation is supplied to many (not just acinar) salivary grand cells, although there is some variation between glands in the extent of sympathetic input $[23,24]$. In animal models sympathetic stimulation produces a different protein-rich saliva, and mucin production from mucous glands seems to be initiated by parasympathetic stimulation [25]. As a result, whole salivary composition is believed to be influenced by stimulation and the rate of secretion, although this may be mainly related to dilution effects of molecules from non-glandular sources. Many components of freshly secreted saliva are actively secreted by acinar and ductal cells and so these will not be altered, with the exception of sodium, chloride and bicarbonate salts, which are more concentrated in stimulated saliva following autonomic stimulation and changes in flow rates [26]. Transport mechanisms include exocytosis of protein storage granules, ion pumps, transport proteins and vesicular proteins [17]. Whole saliva will additionally contain some blood components (including immunoglobulins such as IgG) which have entered as a transudate within the gland system as well as the supplemental materials listed above.

Saliva flow is generally considered to be frequently reduced in older individuals. However, there has been some disagreement on the role of direct age-related changes compared to indirect effects such as the influence of medications that are commonly experienced by older adults. Medications which are known to increase the risk of hyposalivation include anticholinergics, proton pump inhibitors, antidepressants, phenothiazines, benzodiazepines, antihistamines, diuretics and various antihypertensives [27, 28]. Statins have also been reported as being responsible for oral dryness in a small interventional study [29]. Hence salivary volume and composition could further be influenced as an outcome, complication or side effect from systemic disease and treatment (including local radiotherapy and systemic medications). These effects may be direct or indirect, mediated by other pathways such as dehydration, which may itself be related to impaired fluid intake, emesis, diarrhoea or polyuria.

The current opinion based on primary research and systematic reviews $[30,31]$ is that there is an age-related decrease in salivary gland function and thus in xerostomia, and that medication merely enhances this further. However, the primary research is somewhat contradictory for age-related changes in both unstimulated [32-35] and in stimulated [35-38] salivary flow rate, and large inter-individual differences between participants within study groups have been reported. Nagler and 
Hershkovich [39] have shown how there is not only a change in volume but also composition (including ions, immunoglobulins and other proteins) with aging, although their participants were taking a range of medications to maintain health. However, this was confirmed in a large cross-sectional study by Dodds et al. [40]. Consequently, it would seem that saliva flow is impaired in older populations, and that aging can also modify the composition of saliva produced. It would seem necessary to accommodate this into study design and data analysis if possible when determining the value of biomarkers in populations of differing or mixed ages.

Finally, psychogenic causes, such as depression, anxiety or stress, can also result in xerostomia mediated by sympathetic stimulation. In cases of $\mathrm{AD}$, stroke or other neurological pathology, patients may complain of dry mouth in the presence of reduced or normal salivary secretion due to altered production [41]. Hence self-reported dryness in some patients may not by itself be an exclusion factor for attempted salivary sampling-it would seem wise to confirm this with intraoral examination even if ultimately collection is unsatisfactory. The impact of these challenges is illustrated by the observations recently reported by Galloway et al. [42] that approximately $1 / 3$ of participants in the recent UK Biobank study were unable to produce an adequate saliva sample, and that this was noticeably increased amongst those with a range of systemic diseases. Indeed only $57.7 \%$ of participants with a diagnosis including dementia, AD or Parkinson's diseases (PD) were able to produce an adequate sample for archiving (Table 1). Therefore, it appears that results from salivary analysis, whilst offering excellent potential as a research and management tool, may have to be considered carefully allowing for age, concurrent medication and other risk factors. Each of these factors may independently have an impact on data and these variables should at least be recorded in clinical studies. Likewise, there may be issues with obtaining adequate samples for some participants, especially the elderly and/or those with significant systemic disease.

\section{CURRENT EVIDENCE OF SALIVARY BIOMARKERS FOR ALZHEIMER'S DISEASE AND RELATED DISORDERS}

\section{Amyloid- $\beta$}

The accumulation of $A \beta$ plaques, the foremost hallmark of $\mathrm{AD}$, begins $15-20$ years prior to the clinical onset of cognitive and functional decline [43]. Visually assessed and quantitative positron emission tomography (PET) studies using ${ }^{11} \mathrm{C}$ and ${ }^{18} \mathrm{~F} \mathrm{~A} \beta$ tracers have consistently verified increased retention in AD dementia and preclinical $\mathrm{AD}$ when compared with elderly controls, with the binding typically elevated in the frontal, cingulate, precuneus, striatum, parietal and lateral temporal cortices [1]. This regional distribution visualised by $\mathrm{A} \beta$ PET closely follows the categorisation of $A \beta$ burden in post-mortem studies [44]. More recently, it has been confirmed that CSF A $\beta 42$ is also a reliable marker of amyloid plaque pathology in the brain (as determined at autopsy or through $\mathrm{A} \beta$ PET studies [45]), especially when measured in a ratio with CSF $A \beta 40$. The assessment of $A \beta$ by PET or CSF immunoassays is now included in research criteria for $\mathrm{AD}$ [46] as well as in the biological definition of the disease [47]. A $\beta$ peptides can be readily measured in plasma utilising ultra-sensitive immunoassays $[5,6]$ or targeted mass spectrometry (MS) [3] and emerging evidence suggests that a decreased $A \beta$ peptide ratio can identify cerebral $A \beta$-positive individuals with high sensitivity and specificity (Table 2).

The widespread peripheral expression of the amyloid precursor protein (APP) would make it seemingly likely that $A \beta$ peptides are present in saliva via interaction with blood or degradation of buccal cells [48]. Indeed, a collection of studies have shown that salivary $\mathrm{A} \beta 42$ is detectable and increased in $\mathrm{AD}$ [49-53], with A $\beta 40$ remaining unchanged. Lee et al. [49] have so far demonstrated the most encouraging findings of salivary $A \beta 42$. In this study, thioflavin $S$ was added to the salivary sample at collection to inhibit the aggregation of $A \beta$ and a twofold increase in salivary $A \beta 42$ concentration was observed in $\mathrm{AD}$ compared to controls and 
Table 1 Number of UK Biobank participants with selected health conditions (non-cancerous) who attempted to produce a saliva sample at baseline assessment (selected data, adapted from Galloway et al. [42])

\begin{tabular}{lcl}
\hline Participant groups (selected) & Samples attempted & Samples adequate (\%) \\
\hline All participants in UK BioBanks & 120,175 & $84,721(70.5)$ \\
Diabetes mellitus & 743 & $4787(64.4)$ \\
Cerebrovascular disease & 2723 & $1725(63.3)$ \\
Ischemic heart disease & 6839 & $4474(65.4)$ \\
Alzheimer's and Parkinson's disease & 284 & $164(57.7)$ \\
Clinical depression & 7632 & $5006(65.6)$ \\
Chronic obstructive pulmonary disease & 1245 & $739(59.4)$ \\
Asthma & 14,442 & $10,040(69.5)$ \\
Inflammatory bowel disease & 3524 & $2354(66.8)$ \\
Rheumatoid arthritis & 1447 & $919(63.5)$ \\
Osteoporosis & 2652 & $1721(64.9)$ \\
Acute renal failure/Chronic kidney disease & 679 & $415(61.1)$ \\
\hline
\end{tabular}

patients with PD. An earlier study has also demonstrated an increase of salivary $A \beta 42$ in $\mathrm{AD}$ compared to PD but these significant findings were confined to mild $\mathrm{AD}$ and not observed in severe $\mathrm{AD}$ [50]. These small pilot studies point towards salivary A $\beta 42$ being a potentially specific and early biomarker for AD. However, it must be noted that $\mathrm{A} \beta 42$ has also been demonstrated to be unchanged or not detectable in studies using similar antibodybased methodologies [54, 55]. These inconsistent results are similar to the early reports of A 342 in plasma which also utilised standard sandwich enzyme-linked immunosorbent assays [56]. The application of ultra-sensitive immunoassays (e.g. Simoa or SMx-Pro) or targeted MS for salivary $\mathrm{A} \beta$ may render more consistent results. Furthermore, no study has yet to compare salivary $A \beta 42$ to $A \beta$-positive confirmed $A D$ or tested the salivary $A \beta 42 / A \beta 40$ ratio which may improve the diagnostic accuracy.

\section{Tau}

An aggregated and phosphorylated form of tau protein is the major constituent of neurofibrillary tangles (NFT) in AD. First-generation tau
PET ligands show elevated retention in patients with $\mathrm{AD}$, as compared to controls, with uptake patterns matching histopathology staging schemes for tau [2]. The second-generation tau ligands (e.g. $\left[{ }^{18} \mathrm{~F}\right] \mathrm{MK}-6240,\left[{ }^{18} \mathrm{~F}\right] \mathrm{RO}-948$, and $\left.\left[{ }^{18} \mathrm{~F}\right] \mathrm{GTP}-1\right)$ appear to be superior and this is due to their reduced off-target binding to iron, neuromelanin and monoamine oxidase B [2]. The core CSF biomarkers for AD include total tau (T-tau) and tau phosphorylated at threonine 181 (P-tau). Consistently, clinical studies have shown an increase of these biomarkers in $\mathrm{AD}$ and in patients with mild cognitive impairment (MCI) [56]. However, the concentrations of these markers are within the normal range in the majority of other primary tauopathies. In blood, increases in plasma T-tau reach statistical significance in large $\mathrm{AD}$ cohorts $[57,58]$. However, the substantial overlaps between control groups and the poor correlations with CSF levels certainly limit plasma T-tau as being diagnostically useful [57]. The reason for this may be explained by the rapid degradation of tau in blood with a reduced halflife compared to CSF [59]. Preliminary data demonstrating increases of P-tau [9] and 
Table 2 Summary of salivary biomarkers investigated in Alzheimer's disease

\begin{tabular}{|c|c|c|c|}
\hline Biomarker & Proteomic platform & Observations in $\mathrm{AD}$ & References \\
\hline \multirow[t]{3}{*}{ AChE } & \multirow{3}{*}{$\begin{array}{l}\text { Ellman colorimetric } \\
\text { method }\end{array}$} & Decreased (versus healthy controls, $p<0.005$ ) & Sayer et al. [80] \\
\hline & & No change & Bakhtiari et al. [81] \\
\hline & & No change & Boston et al. [82] \\
\hline \multirow[t]{7}{*}{$\mathrm{A} \beta 42$} & \multirow[t]{5}{*}{ Sandwich ELISA } & Increased (versus healthy controls, $p<0.05$ ) & Sabbagh et al. [52] \\
\hline & & Increased (versus healthy controls, $p<0.001$ ) & McGeer et al. [53] \\
\hline & & Increased (versus healthy controls, $p<0.001$ ) & Lee et al. [49] \\
\hline & & Increased (versus healthy controls, $p<0.05$ ) & $\begin{array}{l}\text { Bermejo-Pareja et al. } \\
\quad[50]\end{array}$ \\
\hline & & Not detectable & Lau et al. [54] \\
\hline & Luminex ELISA & Not detectable & Shi et al. [55] \\
\hline & Nanobead ELISA & Increased (versus healthy controls, $p<0.001$ ) & Kim et al. $[51]$ \\
\hline \multirow[t]{2}{*}{$\mathrm{A} \beta 40$} & Sandwich ELISA & No change & $\begin{array}{l}\text { Bermejo-Pareja et al. } \\
\quad[50]\end{array}$ \\
\hline & Nanobead ELISA & & Kim et al. [51] \\
\hline Lactoferrin & Sandwich ELISA & Decreased (versus healthy controls, $p<0.001$ ) & Carro et al. [79] \\
\hline \multirow[t]{3}{*}{ T-tau } & Simoa & No change & Ashton et al. [61] \\
\hline & Sandwich ELISA & No change & Lau et al. [54] \\
\hline & Luminex ELISA & No change & Shi et al. [55] \\
\hline \multirow[t]{2}{*}{ P-tau } & Luminex ELISA & $\begin{array}{l}\text { Increased } \mathrm{p} 181 / \mathrm{T} \text {-tau (versus healthy controls, } \\
\qquad p<0.05 \text { ) }\end{array}$ & Shi et al. [55] \\
\hline & Western blot & $\begin{array}{l}\text { Increased s396/T-tau (versus healthy controls, } \\
\qquad p<0.05 \text { ) }\end{array}$ & Pekeles et al. [62] \\
\hline
\end{tabular}

N-terminal tau [60] in the blood of patients with $\mathrm{AD}$ offer an exciting avenue for blood biomarkers.

We have recently reported the largest $\mathrm{AD}$ salivary biomarker study which consisted of 160 age-matched controls, 68 participants with MCI, and 53 participants with AD [61]. Furthermore, this was the first study to utilise an ultrasensitive single molecule array (Simoa) assay to measure T-tau concentration in saliva. However, we found no statistically significant differences across these diagnostic groups. Interestingly, T-tau was detectable in more than 95\% of all participants and the concentration was approximately fourfold higher than that in plasma (cohort mean, $11.85 \mathrm{ng} / \mathrm{L}$ ). In addition, we demonstrated that there was no association of salivary T-tau with cognitive scores or atrophy measures. This study confirms the preliminary findings by two earlier studies $[54,55]$. Shi and colleagues confirmed the presence of tau in saliva by identifying five unique peptide sequences by MS. A subsequent Luminex assay (based on mid-domain tau antibodies) demonstrated no change of salivary T-tau. However, a 1.3-fold increase of the salivary P-tau181/T-tau was observed in $\mathrm{AD}$ [55]. In a similar manner, Lau et al. demonstrated no change in salivary T-tau but increases in P-tau [54]. A study using semi-quantitative proteomics investigated a 
number phosphorylation sites in saliva [62]. In a ratio with T-tau, phosphospecific antibodies for serine 396 demonstrated increases in $\mathrm{AD}$, while serine 404 was increased in frontotemporal dementia (FTD). However, no association could be drawn with brain atrophy or CSF measures of tau. Furthermore, this study reported no change of P-tau181 in patients with AD. While data on salivary T-tau is consistently negative, phosphorylated tau species in saliva may have greater utility. However, as with P-tau in blood, ultra-sensitive assays are still being refined for reliable detection of P-tau in peripheral fluids.

The presence of tau in saliva may have a number of sources. In a similar manner to $A \beta$, interactions with the bloodstream or release from buccal cells is likely given that elevated tau isoform levels in isolated buccal cells have been shown in AD [63]. Furthermore, salivary tau may originate from acinar cells that express tau mRNA [64] or nerves that innervate the salivary glands.

\section{Alpha-synuclein}

The presynaptic neuronal protein alpha-synuclein ( $\alpha$-syn) is the most abundant protein of the intracellular aggregates found in Lewy bodies in PD, dementia with Lewy bodies (DLB) and in glial cytoplasmic inclusions of multiple system atrophy [65]. However, a truncated form of $\alpha$-syn (termed non-amyloid component or $\mathrm{NAC}$ ) is also a major component in the $\mathrm{A} \beta$ plaques in patients with $\mathrm{AD}$ [66]. CSF biomarkers for $\alpha$-syn pathology have been a challenging task but a general trend has emerged of decreased total $\alpha$-syn and an increase in phosphorylated and oligomeric $\alpha$-syn in PD $[67,68]$, while level of total $\alpha$-syn is markedly increased in AD and correlates with T-tau [69], which may suggest that total $\alpha$-syn largely reflects neurodegeneration or synaptic damage [70].

Post-mortem submandibular gland biopsies are positive for Lewy-type $\alpha$-syn in patients with PD but not in healthy subjects [71], and this finding has made salivary $\alpha$-syn one of the most investigated salivary biomarkers in neurodegeneration. Yet, both increases and decreases in salivary total $\alpha$-syn have been reported [72-74]. On the other hand, increases in oligomeric $\alpha$ syn [75] and oligomeric $\alpha$-syn/total $\alpha$-syn ratio have been demonstrated to be specific for PD $[74,76]$. To date, there has been no investigation of salivary $\alpha$-syn in AD. In addition to $\alpha$ syn, a mutation in the protein DJ-1 has been associated with rare early onset familial autosomal recessive PD. Preliminary data appear to show increases in PD [72, 77, 78] and correlate with motor disability [78].

\section{Lactoferrin}

Lactoferrin is an antimicrobial peptide with $A \beta$ binding properties which targets bacteria and is abundantly present in human saliva. Carro et al. [79], using an initial MS discovery and subsequent ELISA validation, have shown a substantially decreased concentration of lactoferrin in patients with MCI and patients compared to aged-matched controls, while patients with PD exhibited higher concentrations than controls. In patients with $\mathrm{AD}$, unstimulated lactoferrin was also positively correlated with Mini-Mental State Examination (MMSE) score and CSF A $\beta 42$ while being negatively correlated to T-tau. In a follow-up study, a concentration cut-off $(7.43 \mu \mathrm{g} / \mathrm{mL})$ successfully discriminated people with AD from controls participants. Finally, lactoferrin may have potential in early disease detection. In a longitudinal study, 78\% of control participants that presented with "AD-like" concentrations of lactoferrin $(<7.43 \mu \mathrm{g} / \mathrm{mL})$ converted to an MCI or AD diagnosis within 5 years of the baseline collection. None of the control participants with "normal" lactoferrin $(>7.43 \mu \mathrm{g} / \mathrm{mL}$ ) changed clinical status within the same time frame.

\section{Acetylcholinesterase}

In $\mathrm{AD}$, acetylcholinesterase inhibitors (AChE-I) are the primary drug prescribed for symptom management which mechanistically encourage an increase in acetylcholine (AChE) neurotransmitter release into the synapse cleft.

The activity of AChE in saliva can be measured by the Ellman colorimetric method, 
where decreases are seen with age but also further reduced in people with $\mathrm{AD}$ compared to aged-matched controls [80-82], albeit not all studies reaching statistical significance. In addition to these findings, within the AD population, AChE is significantly decreased further in AChE-I non-responders when compared to AChE-I responders [80]. In PD, a single report demonstrates an increase in AChE activity compared with age-matched controls, which was an indicator of disease progression as indexed by the Hoehn and Yahr scale [83].

\section{CONCLUSIONS}

In the last decade, there has been considerable advancement in the detection of AD-related biomarkers in non-invasive peripheral materials, such as blood. This remarkable and rapid success has posed a new challenge-can other peripheral sources be utilised for AD-related biomarkers, namely saliva? The data currently available shows that $A \beta 42, A \beta 40$ and multiple tau species are all detectable in saliva using conventional immunoassays. While salivary $\mathrm{A} \beta 40$ and T-tau are not related to clinical AD disease, increases in $A \beta 42$, phosphorylated tau species and decreases in lactoferrin may have potential. Yet, how salivary $A \beta 42$ relates to brain amyloid metabolism, to CSF or plasma levels of $A \beta 42$, or to brain amyloidosis evaluated by $A \beta$ PET status is not known. On the other hand, the antimicrobial peptide lactoferrin has been shown to correlate well with $\mathrm{AD}$ CSF biomarkers and to detect preclinical AD. In PD, multiple forms of $\alpha$-syn have been investigated, with oligomeric $\alpha$-syn being the most promising for disease diagnosis. Although the non-invasive nature of saliva is an attractive attribute there remain important considerations. Firstly, standardisation in collection (e.g. stimulated versus unstimulated), pre-processing (e.g. centrifugation speeds) and storage (e.g. addition of sodium azide) is currently lacking. While the majority of studies included in this review analysed unstimulated whole saliva, there are very clear distinctions in proteome content between unstimulated and stimulated collections from different glands. It is currently not known how the concentrations of $\mathrm{A} \beta$, tau and other biomarkers discussed in this review differ between sublingual, parotid, whole unstimulated and stimulated saliva or if their presence in saliva is simply from blood. Secondly, while the successful collection of blood and CSF from a consenting participant is driven by a physician, the access to unstimulated saliva is solely dependent on the participant. This is likely to create large variabilities in the material collected and therefore stimulated saliva could be a preferred method due to the simplicity of the collection method. As previously mentioned, there is substantial evidence available to demonstrate that elderly patients, particularly suffering with dementia, find it difficult to produce an adequate saliva sample. For these reasons, a saliva biomarker would be more suitable for the preclinical phase of disease and not for individuals with significant cognitive impairment. At this moment in time, the limited data in large well-characterised and, in some cases, conflicting reports means we are unable to conclude this with any real certainty. Nonetheless, the current research reviewed in this article cautiously indicates the potential of saliva as a non-invasive biomarker source at the preclinical phase of the disease which should be further investigated to determine the reliability of such biomarkers in detecting disease pathology or monitoring disease progression.

\section{ACKNOWLEDGEMENTS}

Funding. No funding or sponsorship was received for this study or publication of this article.

Authorship. All named authors meet the International Committee of Medical Journal Editors (ICMJE) criteria for authorship for this article, take responsibility for the integrity of the work as a whole, and have given their approval for this version to be published.

Disclosures. Nicholas J. Ashton is funded by the Wallenberg Centre for Molecular and Translational. Henrik Zetterberg is a Wallenberg 
Academy Fellow supported by grants from the Swedish Research Council (\#2018-02532), the European Research Council (\#681712), Swedish State Support for Clinical Research (\#ALFGBG720931) and the UK Dementia Research Institute at UCL. Henrik Zetterberg has served at scientific advisory boards for Roche Diagnostics, Wave, Samumed and CogRx, has given lectures in symposia sponsored by Alzecure and Biogen, and is a co-founder of Brain Biomarker Solutions in Gothenburg AB, a GU Ventures-based platform company at the University of Gothenburg. Kaj Blennow is supported by the Torsten Söderberg Foundation, Stockholm, Sweden. Kaj Blennow has served as a consultant or at advisory boards for Alector, Alzheon, CogRx, Biogen, Lilly, Novartis and Roche Diagnostics, and is also a co-founder of Brain Biomarker Solutions in Gothenburg AB. Mark Ide has nothing to disclose.

Compliance with Ethics Guidelines. This article is based on previously conducted studies and does not contain any studies with human participants or animals performed by any of the authors.

Open Access. This article is distributed under the terms of the Creative Commons Attribution-NonCommercial 4.0 International License (http://creativecommons.org/licenses/ by-nc/4.0/), which permits any noncommercial use, distribution, and reproduction in any medium, provided you give appropriate credit to the original author(s) and the source, provide a link to the Creative Commons license, and indicate if changes were made.

\section{REFERENCES}

1. Ashton NJ, Scholl M, Heurling K, et al. Update on biomarkers for amyloid pathology in Alzheimer's disease. Biomark Med. 2018;12(7):799-812.

2. Scholl M, Maass A, Mattsson N, et al. Biomarkers for tau pathology. Mol Cell Neurosci. 2019;97:18-33.

3. Nakamura A, Kaneko N, Villemagne VL, et al. High performance plasma amyloid-beta biomarkers for
Alzheimer's disease. Nature. 2018;554(7691): 249-54.

4. Janelidze S, Stomrud E, Palmqvist S, et al. Plasma beta-amyloid in Alzheimer's disease and vascular disease. Sci Rep. 2016;6:26801.

5. Vergallo A, Megret L, Lista S, et al. Plasma amyloid beta 40/42 ratio predicts cerebral amyloidosis in cognitively normal individuals at risk for Alzheimer's disease. Alzheimers Dement. 2019;15(6): 764-75.

6. Palmqvist S, Janelidze S, Stomrud E, et al. Performance of fully automated plasma assays as screening tests for Alzheimer disease-related beta-amyloid status. JAMA Neurol. 2019;76(9):1060-9.

7. Mattsson N, Cullen NC, Andreasson U, Zetterberg $\mathrm{H}$, Blennow K. Association between longitudinal plasma neurofilament light and neurodegeneration in patients with Alzheimer disease. JAMA Neurol. 2019;76(7):791-9.

8. Ashton NJ, Leuzy A, Lim YM, et al. Increased plasma neurofilament light chain concentration correlates with severity of post-mortem neurofibrillary tangle pathology and neurodegeneration. Acta Neuropathol Commun. 2019;7(1):5.

9. Mielke MM, Hagen CE, Xu J, et al. Plasma phosphotau181 increases with Alzheimer's disease clinical severity and is associated with tau- and amyloidpositron emission tomography. Alzheimers Dement. 2018;14(8):989-97.

10. Hampel H, O'Bryant SE, Molinuevo JL, et al. Bloodbased biomarkers for Alzheimer disease: mapping the road to the clinic. Nat Rev Neurol. 2018;14(11): 639-52.

11. Zhang Y, Sun J, Lin CC, Abemayor E, Wang MB, Wong DT. The emerging landscape of salivary diagnostics. Periodontol 2000. 2016;70(1):38-52.

12. Bonne NJ, Wong DT. Salivary biomarker development using genomic, proteomic and metabolomic approaches. Genome Med. 2012;4(10):82.

13. Farah R, Haraty H, Salame Z, Fares Y, Ojcius DM, Said Sadier N. Salivary biomarkers for the diagnosis and monitoring of neurological diseases. Biomed J. 2018;41(2):63-87.

14. Spielmann N, Wong DT. Saliva: diagnostics and therapeutic perspectives. Oral Dis. 2011;17(4): 345-54.

15. Jasim $\mathrm{H}$, Olausson $\mathrm{P}$, Hedenberg-Magnusson $\mathrm{B}$, Ernberg M, Ghafouri B. The proteomic profile of whole and glandular saliva in healthy pain-free subjects. Sci Rep. 2016;6:39073. 
16. Jasim H, Carlsson A, Hedenberg-Magnusson B, Ghafouri B, Ernberg M. Saliva as a medium to detect and measure biomarkers related to pain. Sci Rep. 2018;8(1):3220.

17. Proctor GB. The physiology of salivary secretion. Periodontol 2000. 2016;70(1):11-25.

18. Boros I, Keszler P, Zelles T. Study of saliva secretion and the salivary fluoride concentration of the human minor labial glands by a new method. Arch Oral Biol. 1999;44(Suppl 1):S59-62.

19. Veerman EC, van den Keybus PA, Vissink A, Nieuw Amerongen AV. Human glandular salivas: their separate collection and analysis. Eur J Oral Sci. 1996;104(4 (Pt 1)):346-52.

20. Lee VM, Linden RW. An olfactory-submandibular salivary reflex in humans. Exp Physiol. 1992;77(1): 221-4.

21. Lee A, Guest S, Essick G. Thermally evoked parotid salivation. Physiol Behav. 2006;87(4):757-64.

22. Edgar WM. Saliva and dental health. Clinical implications of saliva: report of a consensus meeting. Br Dent J. 1990;169(3-4):96-8.

23. Garrett JR, Anderson LC. Rat sublingual salivary glands: secretory changes on parasympathetic or sympathetic nerve stimulation and a reappraisal of the adrenergic innervation of striated ducts. Arch Oral Biol. 1991;36(9):675-83.

24. Rossoni RB, Machado AB, Machado CR. A histochemical study of catecholamines and cholinesterases in the autonomic nerves of the human minor salivary glands. Histochem J. 1979;11(6): 661-8.

25. Culp DJ, Graham LA, Latchney LR, Hand AR. Rat sublingual gland as a model to study glandular mucous cell secretion. Am J Physiol. 1991;260(6 Pt 1):C1233-44.

26. Lee MG, Ohana E, Park HW, Yang D, Muallem S. Molecular mechanism of pancreatic and salivary gland fluid and $\mathrm{HCO}_{3}$ secretion. Physiol Rev. 2012;92(1):39-74.

27. Sreebny LM, Schwartz SS. A reference guide to drugs and dry mouth-2nd edition. Gerodontology. 1997;14(1):33-47.

28. Hassona Y, Scully C. Salivary changes in oral mucosal diseases. Periodontol 2000. 2016;70(1): 111-27.

29. Pascual Cruz M, Chimenos Kustner E, Garcia Vicente JA, Mezquiriz Ferrero X, Borrell Thio E, Lopez Lopez J. Adverse side effects of statins in the oral cavity. Med Oral Patol Oral Cir Bucal. 2008;13(2): E98-101.

30. Liu B, Dion MR, Jurasic MM, Gibson G, Jones JA. Xerostomia and salivary hypofunction in vulnerable elders: prevalence and etiology. Oral Surg Oral Med Oral Pathol Oral Radiol. 2012;114(1):52-60.

31. Affoo RH, Foley N, Garrick R, Siqueira WL, Martin RE. Meta-analysis of salivary flow rates in young and older adults. J Am Geriatr Soc. 2015;63(10): 2142-51.

32. Heft MW, Baum BJ. Unstimulated and stimulated parotid salivary flow rate in individuals of different ages. J Dent Res. 1984;63(10):1182-5.

33. Speight PM, Kaul A, Melsom RD. Measurement of whole unstimulated salivary flow in the diagnosis of Sjogren's syndrome. Ann Rheum Dis. 1992;51(4): 499-502.

34. Percival RS, Challacombe SJ, Marsh PD. Flow rates of resting whole and stimulated parotid saliva in relation to age and gender. J Dent Res. 1994;73(8): 1416-20.

35. Jones RE, Ship JA. Major salivary gland flow rates in young and old, generally healthy African Americans and whites. J Natl Med Assoc. 1995;87(2): $131-5$.

36. Ship JA, Baum BJ. Is reduced salivary flow normal in old people? Lancet. 1990;336(8729):1507.

37. Ghezzi EM, Lange LA, Ship JA. Determination of variation of stimulated salivary flow rates. J Dent Res. 2000;79(11):1874-8.

38. Smith $\mathrm{CH}$, Boland B, Daureeawoo Y, Donaldson E, Small K, Tuomainen J. Effect of aging on stimulated salivary flow in adults. J Am Geriatr Soc. 2013;61(5): 805-8.

39. Nagler RM, Hershkovich O. Age-related changes in unstimulated salivary function and composition and its relations to medications and oral sensorial complaints. Aging Clin Exp Res. 2005;17(5):358-66.

40. Dodds MW, Johnson DA, Yeh CK. Health benefits of saliva: a review. J Dent. 2005;33(3):223-33.

41. Gupta A, Epstein JB, Sroussi H. Hyposalivation in elderly patients. J Can Dent Assoc. 2006;72(9): 841-6.

42. Galloway JW, Keijser BJ, Williams DM. Saliva in studies of epidemiology of human disease: the UK Biobank project. Periodontol 2000. 2016;70(1): 184-95. 
43. Jack CR Jr, Knopman DS, Jagust WJ, et al. Tracking pathophysiological processes in Alzheimer's disease: an updated hypothetical model of dynamic biomarkers. Lancet Neurol. 2013;12(2):207-16.

44. Ikonomovic MD, Klunk WE, Abrahamson EE, et al. Post-mortem correlates of in vivo PiB-PET amyloid imaging in a typical case of Alzheimer's disease. Brain. 2008;131(Pt 6):1630-45.

45. Mattsson N, Insel PS, Donohue M, et al. Independent information from cerebrospinal fluid amyloidbeta and florbetapir imaging in Alzheimer's disease. Brain. 2015;138(Pt 3):772-83.

46. Dubois B, Feldman HH, Jacova C, et al. Advancing research diagnostic criteria for Alzheimer's disease: the IWG-2 criteria. Lancet Neurol. 2014;13(6): 614-29.

47. Jack CR Jr, Bennett DA, Blennow K, et al. NIA-AA research framework: toward a biological definition of Alzheimer's disease. Alzheimers Dement. 2018;14(4):535-62.

48. Francois M, Fenech MF, Thomas $\mathrm{P}$, et al. High content, multi-parameter analyses in buccal cells to identify Alzheimer's disease. Curr Alzheimer Res. 2016;13(7):787-99.

49. Lee M, Guo JP, Kennedy K, McGeer EG, McGeer PL. A method for diagnosing Alzheimer's disease based on salivary amyloid-beta protein 42 levels. J Alzheimers Dis. 2017;55(3):1175-82.

50. Bermejo-Pareja F, Antequera D, Vargas T, Molina JA, Carro E. Saliva levels of Abeta1-42 as potential biomarker of Alzheimer's disease: a pilot study. BMC Neurol. 2010;10:108.

51. Kim CB, Choi YY, Song WK, Song KB. Antibodybased magnetic nanoparticle immunoassay for quantification of Alzheimer's disease pathogenic factor. J Biomed Opt. 2014;19(5):051205.

52. Sabbagh MN, Shi J, Lee $M$, et al. Salivary beta amyloid protein levels are detectable and differentiate patients with Alzheimer's disease dementia from normal controls: preliminary findings. BMC Neurol. 2018;18(1):155.

53. McGeer PL, Guo JP, Lee M, Kennedy K, McGeer EG. Alzheimer's disease can be spared by nonsteroidal anti-inflammatory drugs. J Alzheimers Dis. 2018;62(3):1219-22.

54. Lau HC, Lee IK, Ko PW, et al. Non-invasive screening for Alzheimer's disease by sensing salivary sugar using Drosophila cells expressing gustatory receptor (Gr5a) immobilized on an extended gate ion-sensitive field-effect transistor (EG-ISFET) biosensor. PLoS One. 2015;10(2):e0117810.
55. Shi M, Sui YT, Peskind ER, et al. Salivary tau species are potential biomarkers of Alzheimer's disease. J Alzheimers Dis. 2011;27(2):299-305.

56. Olsson B, Lautner R, Andreasson U, et al. CSF and blood biomarkers for the diagnosis of Alzheimer's disease: a systematic review and meta-analysis. Lancet Neurol. 2016;15(7):673-84.

57. Mattsson N, Zetterberg H, Janelidze S, et al. Plasma tau in Alzheimer disease. Neurology. 2016;87(17): 1827-35.

58. Zetterberg H, Wilson D, Andreasson U, et al. Plasma tau levels in Alzheimer's disease. Alzheimers Res Ther. 2013;5(2):9.

59. Randall J, Mortberg E, Provuncher GK, et al. Tau proteins in serum predict neurological outcome after hypoxic brain injury from cardiac arrest: results of a pilot study. Resuscitation. 2013;84(3): 351-6.

60. Chen Z, Mengel D, Keshavan A, et al. Learnings about the complexity of extracellular tau aid development of a blood-based screen for Alzheimer's disease. Alzheimers Dement. 2019;15(3): 487-96.

61. Ashton NJ, Ide M, Scholl M, et al. No association of salivary total tau concentration with Alzheimer's disease. Neurobiol Aging. 2018;70:125-7.

62. Pekeles H, Qureshi HY, Paudel HK, Schipper HM, Gornistky M, Chertkow H. Development and validation of a salivary tau biomarker in Alzheimer's disease. Alzheimers Dement (Amst). 2019;11:53-60.

63. Hattori $\mathrm{H}$, Matsumoto $\mathrm{M}$, Iwai $\mathrm{K}$, et al. The tau protein of oral epithelium increases in Alzheimer's disease. J Gerontol A Biol Sci Med Sci. 2002;57(1): M64-70.

64. Conrad C, Vianna C, Freeman M, Davies P. A polymorphic gene nested within an intron of the tau gene: implications for Alzheimer's disease. Proc Natl Acad Sci USA. 2002;99(11):7751-6.

65. Brinkmalm A, Portelius E, Brinkmalm G, et al. Fluid-based proteomics targeted on pathophysiological processes and pathologies in neurodegenerative diseases. J Neurochem. 2018. https://doi.org/ 10.1111/jnc. 14594 .

66. Bisaglia M, Trolio A, Bellanda M, Bergantino E, Bubacco L, Mammi S. Structure and topology of the non-amyloid-beta component fragment of human alpha-synuclein bound to micelles: implications for the aggregation process. Protein Sci. 2006;15(6): 1408-16. 
67. Kang JH, Mollenhauer B, Coffey CS, et al. CSF biomarkers associated with disease heterogeneity in early Parkinson's disease: the Parkinson's Progression Markers Initiative study. Acta Neuropathol. 2016;131(6):935-49.

68. Parnetti L, Cicognola C, Eusebi P, Chiasserini D. Value of cerebrospinal fluid alpha-synuclein species as biomarker in Parkinson's diagnosis and prognosis. Biomark Med. 2016;10(1):35-49.

69. Ohrfelt A, Grognet P, Andreasen N, et al. Cerebrospinal fluid alpha-synuclein in neurodegenerative disorders-a marker of synapse loss? Neurosci Lett. 2009;450(3):332-5.

70. Liguori C, Olivola E, Pierantozzi M, et al. Cerebrospinal-fluid Alzheimer's disease biomarkers and blood-brain barrier integrity in a natural population of cognitive intact Parkinson's disease patients. CNS Neurol Disord Drug Targets. 2017;16(3): 339-45.

71. Beach TG, Adler CH, Serrano G, et al. Prevalence of submandibular gland synucleinopathy in Parkinson's disease, dementia with Lewy bodies and other Lewy body disorders. J Parkinsons Dis. 2016;6(1): 153-63.

72. Devic I, Hwang H, Edgar JS, et al. Salivary alphasynuclein and DJ-1: potential biomarkers for Parkinson's disease. Brain. 2011;134(Pt 7):e178.

73. Al-Nimer MS, Mshatat SF, Abdulla HI. Saliva alphasynuclein and a high extinction coefficient protein: a novel approach in assessment biomarkers of Parkinson's disease. N Am J Med Sci. 2014;6(12): 633-7.

74. Vivacqua G, Latorre A, Suppa A, et al. Abnormal salivary total and oligomeric alpha-synuclein in Parkinson's disease. PLoS One. 2016;11(3): e0151156.

75. Kang W, Chen W, Yang Q, et al. Salivary total alpha-synuclein, oligomeric alpha-synuclein and
SNCA variants in Parkinson's disease patients. Sci Rep. 2016;6:28143.

76. Vivacqua G, Suppa A, Mancinelli R, et al. Salivary alpha-synuclein in the diagnosis of Parkinson's disease and progressive supranuclear palsy. Parkinsonism Relat Disord. 2019;63:143-8.

77. Kang WY, Yang Q, Jiang XF, et al. Salivary DJ-1 could be an indicator of Parkinson's disease progression. Front Aging Neurosci. 2014;6:102.

78. Masters JM, Noyce AJ, Warner TT, Giovannoni G, Proctor GB. Elevated salivary protein in Parkinson's disease and salivary DJ-1 as a potential marker of disease severity. Parkinsonism Relat Disord. 2015;21(10):1251-5.

79. Carro E, Bartolome F, Bermejo-Pareja F, VillarejoGalende A, Molina JA, Ortiz P, et al. Early diagnosis of mild cognitive impairment and Alzheimer's disease based on salivary lactoferrin. Alzheimers Dement (Amst). 2017;8:131-8.

80. Sayer R, Law E, Connelly PJ, Breen KC. Association of a salivary acetylcholinesterase with Alzheimer's disease and response to cholinesterase inhibitors. Clin Biochem. 2004;37(2):98-104.

81. Bakhtiari S, Moghadam NB, Ehsani M, Mortazavi H, Sabour S, Bakhshi M. Can salivary acetylcholinesterase be a diagnostic biomarker for Alzheimer? J Clin Diagn Res. 2017;11(1):ZC58-60.

82. Boston PF, Gopalkaje K, Manning L, Middleton L, Loxley M. Developing a simple laboratory test for Alzheimer's disease: measuring acetylcholinesterase in saliva-a pilot study. Int J Geriatr Psychiatry. 2008;23(4):439-40.

83. Fedorova T, Knudsen CS, Mouridsen K, Nexo E, Borghammer P. Salivary acetylcholinesterase activity is increased in Parkinson's disease: a potential marker of parasympathetic dysfunction. Parkinsons Dis. $2015 ; 2015: 156479$. 